Cad.Est.Ling., Campinas, 48(2):195-210, 2006

\title{
O QUE QUEREMOS DIZER QUANDO SUSTENTAMOS A CIRCULAÇÃO DOS SENTIDOS?
}

\author{
DÉCIO ROCHA
}

(UERJ)

\begin{abstract}
RÉSUMÉ Dans cet article, nous nous posons la question de savoir dans quel sens il serait légitime de dire que «le sens circule». Pour ce faire, nous approchons la circulation du sens sous une double optique: tout d'abord, la circulation du sens qui a lieu dans l'espace des interactions verbales, le sens étant le résultat d'un travail dit de «co-construction», comme le préconise Bakhtine; ensuite, deux autres modes de circulation du sens que nous caractérisons comme étant situés dans le temps: la circulation des sens qui se doit à une alternance continue entre formes stabilisées (formes abstraites du dictionnaire, réitérables) et formes en mouvement (non réitérables, que l'on ne comprend qu'à l'intérieur d'une énonciation donnée) et la circulation des sens qui s'explique par le caractère foncièrement hétérogène du sujet et du langage. Ici nous aurons recours à Nietzsche pour poser les bases d'une fonction non-représentationnelle du langage, et à Guattari pour redéfinir la notion de subjectivité. Grosso modo on dirait qu'il s'agit d'un débat qui met en scène la (problématique) rencontre de texte et contexte.
\end{abstract}

\section{INTRODUÇÃO}

Este trabalho tem por objetivo, com base em uma perspectiva discursiva assentada fundamentalmente na noção de enunciação, tematizar a questão da circulação de sentidos. Como entender a referida circulação? O que é que reivindicamos e que rejeitamos quando afirmamos que os sentidos circulam?

Em linhas gerais, nosso interesse estará centrado em um debate que compreenderá minimamente a investigação de dispositivos que se acionam na produção de sentido(s) para um dado enunciado e a explicitação de diferentes modos pelos quais é lícito sustentar que os sentidos circulam ${ }^{1}$. Em outras palavras, o que estará em jogo aqui é, em última instância, o modo como tratamos do encontro entre texto e o chamado plano extraverbal, lugar de interseção problemático e nunca dado de antemão².

${ }^{1}$ Esclarecemos desde já que é sob a ótica da AD desenvolvida a partir do final dos anos sessenta do século XX, com Pêcheux, que os sentidos são pensados como situados num plano em contínua circulação.

${ }^{2}$ A presente discussão parece-nos remeter ao debate que busca articular o verbal (texto) e o extraverbal (contexto) porque, aos nos distanciarmos da perspectiva das semânticas formais, nas quais a questão do sentido coincide com a do valor de verdade de um dado enunciado ou com a das condições que devem ser preenchidas no mundo para que um enunciado exprima uma proposição verdadeira, assumimos que os sentidos (ou melhor, os efeitos de sentido) devem ser buscados nos arranjos (sempre provisórios) decorrentes dos encontros de práticas discursivas e não discursivas. 


\title{
2. METÁFORAS QUE RODEIAM O SENTIDO
}

Meu interesse pelo tema pode ser localizado na tentativa de contribuir para o entendimento das diferentes metáforas a que freqüentemente se recorre quando o que está em jogo é a noção de sentido. Com efeito, quando o objetivo é falar de sentido, são bastante recorrentes na literatura da área expressões que remetem a uma idéia de movimento, de circulação. A título de ilustração, seguem algumas ocorrências do que anuncio:

\footnotetext{
« Chamaremos efeito metafórico o fenômeno semântico produzido por uma substituição contextual para lembrar que esse 'deslizamento ${ }^{3}$ de sentido'entre $x$ e $y$ é constitutivo do 'sentidódesignado por $x$ e $y . "($ Gadet \& Hak, 1990, p. 96)

«...o sentido deve ser apreendido no que há de movente de um [enunciado] a outro, não mais fixado nas intenções de um sujeito-fonte, mas móvel, entre dois sujeitos ${ }^{4}$... » (Peytard \& Moirand, 1992, p. 34-35)

«... os sentidos nunca se dão em definitivo; existem sempre aberturas por onde é possível o movimento da contradição, do deslocamento e da polêmica. » (Gregolin, 2001, p. 61)

«Queremos mostrar como os sentidos vão chegando e se deslocando, tomando cores locais na história de suas formulações ... Podemos assim apreciar o trajeto pelo qual um sentido que se pretende preciso passa a estar em tudo indistintamente ... (...)

... talvez esses deslizamentos de sentido, essa generalização doméstica indistinta, ... esteja mais bem atestada neste outro fragmento ... » (Orlandi, 2002, p.265-266)
}

A profusão de metáforas a que me refiro coloca inicialmente em cena uma certa direção teórica que sustentará o ponto de vista que defendo: os sentidos nunca são um jádado, constituindo, ao contrário, o resultado, parcial e provisório, de um « trabalho » que se realiza. O referido trabalho é algo que pode ser apreendido por intermédio de noções como as de construção ou produção presentes em fragmentos como os que seguem:

\begin{abstract}
« Devido ao seu estatuto heterogêneo, a construção de sentidos e a sua legibilidade podem ser analisadas nas relações ... » (Gregolin, 2001, p.76)

«... seja qual for o lugar assumido para olhar o pensamento bakhtiniano, a idéia do diálogo ... atravessa o campo de visão e desdobra as possibilidades do ver, incluindo incessantemente a história e a memória na cena de produção de sentidos e de seus efeitos. » (Brait, 2001, p.34) «Ter como projeto evidenciar a construção social do sentido na palavra viva situa-nos em uma problemática construtivista na qual se leva em consideração o sujeito enunciador visto como ator da produção de sentido ${ }^{5}$... » (Boutet, 1994, p. 49)
\end{abstract}

O trabalho de construção / produção indicado nos fragmentos citados encontra-se diretamente ligado à historicidade dos sentidos, segundo a perspectiva teórica que dá sustentação à referida produção a que fizemos menção anteriormente. Com efeito, tal perspectiva, assumida por uma certa versão da AD do final dos anos sessenta do século XX comumente identificada como « Análise do discurso de base francesa », preconiza a

\footnotetext{
${ }^{3}$ Grifo nosso, procedimento a ser adotado em todos os fragmentos transcritos neste item.

${ }^{4}$ Tradução nossa, procedimento a ser adotado neste trabalho em relação a todas as obras em língua estrangeira que forem citadas.

${ }^{5}$ Lembramos ainda que a referida obra de Boutet traz no próprio título (Construire le sens) a marca do que se pretende explicitar neste item.
} 
impossibilidade de identificação de um 'lugar estável', 'fixo', no que concerne ao sentido. Assim sendo, quando o sentido se apresenta revestido de uma certa estabilidade, tal estabilidade é um efeito-ilusão necessário criado pela ideologia - efeito que vem sempre acompanhado de seu correlato, o da pretensa existência espontânea do sujeito:

Como todas as evidências, inclusive aquelas que fazem com que uma palavra 'designe uma coisa' ou 'possua um significado' (portanto inclusas as evidências da 'transparência' da linguagem), a evidência de que vocês e eu somos sujeitos ... é um efeito ideológico, o efeito ideológico elementar. (Pêcheux, 1988, p.153)

Assim, a questão da constituição do sentido se encontra com a da constituição do sujeito na figura da interpelação, tema do qual tratará uma teoria materialista do discurso: os indivíduos são interpelados em sujeitos (de seu discurso) «pelas formações discursivas que representam 'na linguagem' as formações ideológicas que lhes são correspondentes" (Pêcheux, 1988, p.161). Eis, deste modo, a produção do efeito-sujeito, a ilusão subjetiva que Pêcheux ironicamente denomina «efeito Münchhausen»:

«É a ideologia que fornece as evidências ... que fazem com que uma palavra ou um enunciado 'queiram dizer o que realmente dizem' e que mascaram, assim, sob a 'transparência da linguagem', aquilo que chamaremos o caráter material do sentido das palavras e dos enunciados. » (Pêcheux, 1988, p. 160)

Percebe-se, desse modo, o fundamento da instabilidade dos sentidos, produtos tão históricos quanto o sujeito:

« ... o sentido de uma palavra, de uma expressão, de uma proposição, etc., não existe 'em si mesmo' (isto é, em sua relação com a literalidade do significante), mas, ao contrário, é determinado pelas posições ideológicas que estão em jogo no processo sócio-histórico no qual as palavras, expressões e proposições são produzida (isto é, reproduzidas). » (Pêcheux, 1988, p. 160)

Ou, de forma mais simples:

«... as palavras, expressões, proposições, etc., mudam de sentido segundo as posições sustentadas por aqueles que as empregam ... » (Pêcheux, 1988, p. 160)

Assim, o que uma formação discursiva faz é dissimular, por intermédio de uma pretensa transparência do sentido, a dependência que mantém em relação ao interdiscurso, ou, como diz Pêcheux, a dependência de uma formação discursiva « com respeito ao 'todo complexo com dominante' das formações discursivas, intrincado no complexo das formações ideológicas ... » (Pêcheux, 1988, p. 162). O primado do interdiscurso - « algo fala sempre antes, em outro lugar e independentemente » (Pêcheux, 1988, p.162) - revela-se, portanto, um fator de decisiva importância no que concerne à produção de efeitos de sentido:

« ... o sentido não é função de significante/palavra ... as palavras têm seu sentido num discurso que remete sempre a ocorrências anteriores. Ou ainda: qualquer enunciação supõe uma posição, e é a partir dessa posição que os enunciados (palavras) recebem seu sentido. Melhor ainda: qualquer uma dessas posições implica uma memória discursiva, de modo que as formulações não nascem de um sujeito que apenas segue as regras de uma língua, mas do interdiscurso, vale dizer, as formulações estão sempre relacionadas a outras formulações. » (Possenti, 2001, p. 50-51) 


\section{O PARTIDO QUE ORA SE DESEJA TOMAR}

Em diversos momentos das reflexões sobre a linguagem foi travado o debate acerca da pertinência de uma abordagem dos fenômenos do sentido que privilegiasse uma perspectiva de maior estabilidade ou de maior movimento.

Como preâmbulo às considerações que ora fazemos, cabe lembrar que, se dizemos que os sentidos circulam, é porque queremos rejeitar um entendimento segundo o qual se diria que os sentidos são fixos, imutáveis, ou que são passíveis de serem localizados em algum ponto preciso do fio do discurso. Não pretendo aqui proceder a nenhum inventário exaustivo dos diferentes modos de abordagem da questão $0^{6}$, mas tão-somente fazer referência a alguns desses modos que se tornaram mais visíveis.

No que diz respeito a abordagens que privilegiaram uma versão predominantemente estável dos sentidos, podemos citar os trabalhos que se desenvolveram em Análise de Conteúdo e no enfoque behaviorista da linguagem.

Inicio pelos trabalhos que consolidaram a perspectiva da denominada Análise de Conteúdo, os quais desenvolveram um modo particular de lidar com a relação entre texto e contexto: os textos eram vistos como índices, pistas que apontavam em direção a uma certa realidade, a saber, a realidade sócio-psicológica de um dado ator, ou de uma categoria de atores, etc. Em outras palavras, o texto era visto como mero pretexto para a captação de algo mais substancial que se produzia em um outro plano: o(s) sentido(s) do texto era $(\mathrm{m})$ exatamente o que era encoberto, escondido, pela materialidade lingüística, a qual deveria ser questionada de modo a nos permitir ver aquilo que se encobria sob o seu véu.

Desse modo, se digo que o enfoque da Análise de Conteúdo privilegia uma versão do sentido como algo de mais estável, de menos movente, é porque, em consonância com o que preconiza o referido enfoque, acredita-se efetivamente que o sentido exista em si e que possa ser localizado de forma plena. A materialidade lingüística assume, desse modo, um estatuto ambíguo: ao mesmo tempo em que encobre o sentido, ou seja, em que oculta aquilo que o texto « quer dizer », também é capaz, por intermédio de « técnicas de leitura », de revelar algo que lá se encontra. O texto é visto como sendo o lugar em que uma dada «verdade » se oculta (a situação sócio-psicológica subjacente à sua produção) e, simultaneamente, se manifesta.

A relação entre a Análise de Conteúdo e a perspectiva behaviorista da linguagem é bastante evidente ${ }^{7}$. No que concerne à questão do sentido, a perspectiva behaviorista da linguagem encontrou um modo categórico de abordar o tema: se algo muda no plano das significações, muda porque a realidade extraverbal se modifica. As significações estão no mundo e, por isso, o lingüista não poderá defini-las, devendo, antes, para tal fim, recorrer a outras ciências e ao saber comum. De forma sintética: não é problema do lingüista o que $x$ significa!

Com efeito, com Bloomfield, a significação de uma forma lingüística corresponde à situação em que o locutor a enuncia e a resposta que ela provoca no ouvinte. (Bloomfield,

${ }^{6}$ Aliás, como veremos adiante, a ênfase da reflexão que desenvolvo neste trabalho pretende incidir não sobre a opção entre uma abordagem dos fenômenos de sentido que privilegie a estabilidade ou o movimento, mas sobre o tipo de movimento empreendido, a saber, movimento no espaço ou movimento no tempo.

${ }^{7}$ Para maiores detalhes, ver Rocha \& Deusdará (2006). 
1970, p.132). Logo, para se ter uma definição cientificamente exata da significação de cada forma da língua, é necessário possuir um saber cientificamente preciso acerca de tudo o que compõe o universo do locutor e também, quando for relevante, de tudo o que se apresenta como resposta do ouvinte. Por extensão, a mudança semântica de uma forma lingüística é apenas « o resultado de uma mudança de seu emprego », isto é, a expansão da forma de um emprego de situações de um certo tipo para situações de um tipo mais amplo.

Como postulado fundamental, cada forma lingüística possui uma significação constante e específica. Bloomfield discute a condição de instabilidade que caracteriza o sentido: por um lado, várias formas lingüísticas são utilizadas para mais de uma situação típica, o que leva o autor a propor que um dos sentidos seja visto como «normal » (ou principal) e os demais como «marginais » (metafóricos ou figurados); por outro, o autor menciona a distância que separa o sentido dicionarizado (denotação, resultado de situações no curso das quais o locutor ouviu uma forma sendo empregada) e a conotação, denominação que inclui diferentes casos (Bloomfield, 1970, p. 144-149): valores suplementares ligados à palavra em função da posição social do locutor; julgamentos a que se procede acerca de uma expressão utilizada - regionalismo, arcaísmo, vocabulário técnico, estrangeirismo, termos eruditos ou gírias; julgamentos que expressam a conveniência ou não do emprego de um termo; intensidades que incidem sobre a escolha de um termo.

Afastado o entendimento segundo o qual os sentidos seriam vistos como fixos, imutáveis, e reafirmando, conseqüentemente, minha opção de ver nas instabilidades do sentido o resultado de um trabalho situado historicamente, pretendo abordar o tema compreendendo-o sob uma dupla perspectiva: a perspectiva de uma circulação dos sentidos no espaço e no tempo. O que se pode entender por cada uma delas?

Em primeiro lugar, direi que os sentidos circulam porque são construídos a várias vozes, incluindo-se também, como já se poderia deduzir de tal ótica caleidoscópica, a voz do próprio co-enunciador. Aqui, a circulação é algo que se dá prioritariamente no espaço, no revezamento de interlocutores que tomam a responsabilidade pela produção de um certo efeito de sentido. Mostrarei por que razão tal entendimento do modo como se atualiza a mobilidade dos sentidos corresponderia ao que considero uma versão fraca da mobilidade.

A seguir, argumentarei no sentido de reafirmar que os sentidos circulam também em duas outras acepções que remetem, por sua vez, a uma circulação operada não mais no espaço, mas no tempo ${ }^{8}$ :

- primeiro, os sentidos circulam porque não podem ser localizados seqüencialmente em nenhum momento preciso: vemo-nos sempre diante de uma alternância de formas fixas (significado), sempre provisórias, as quais ganham movimento (sentido) para, mais

${ }^{8}$ Falo de circulação de sentidos no tempo, mas talvez a escolha do termo circulação fosse mais adequada para indicar exclusivamente o modo de produção de sentidos que se atualiza no espaço, se entendemos por circulação o "movimento ordenado e contínuo de um corpo que se move em círculo(s) ou que descreve um trajeto circular com retorno ao ponto ao ponto de partida" (dicionário Houaiss). Se uso o mesmo termo para me referir aos sentidos que se produzem no tempo, faço-o por pura comodidade de expressão, alertando, contudo, o leitor de que agora o verbo circular deverá coincidir com "mover-se, transitar em diferentes direções"; da mesma forma, circulação remeterá a "movimentação contínua, fluxo, curso, marcha, deslocamento, errância, ausência de rumo certo". 
ROCHA - O que queremos dizer...

tarde, novamente recuperarem uma certa estabilidade. A esse respeito, direi que as formas de dicionário não são um primeiro plano, estável, ao qual viria se somar um segundo plano, variável, um « a mais », um « excesso » que designaríamos «sentido»; a tal ponto de vista linear, preferiremos contrapor uma perspectiva cujo dinamismo reside precisamente no continuum de formas que se produzem, que se cristalizam e que se desfazem para, a seguir, ganharem corpo em outras formas que, por sua vez, também se desfarão, e assim por diante;

- ainda numa acepção que privilegia a inscrição da circulação do sentido no tempo, diremos que o sentido circula porque não é passível de totalização nos limites de um sujeito da razão, isto é, circula porque se produz como multiplicidade de forças, como devir, numa relação de incompatibilidade fundamental com uma perspectiva essencializada de sujeito.

Eis, portanto, colocadas as condições nas quais pretendo aceitar aqui o desafio que consiste em afirmar um modo de conceber o que permanece e o que efetivamente varia nas práticas linguageiras.

\section{BREVE PANORAMA DA MOBILIDADE DOS SENTIDOS NO ESPAÇO}

Um autor que pretendo recuperar aqui para a presente discussão - e com muita ênfase - é Bakhtin, a começar pela distância verificada entre significação (elemento reiterável e idêntico, abstrato; palavra dicionarizada) e tema (estágio superior real da capacidade lingüística de significar que se atualiza com base no aparato técnico da significação; é concreto, não reiterável em função da singularidade do instante histórico da enunciação). Cito um fragmento de Marxismo e filosofia da linguagem:

« o tema da enunciação é determinado não apenas pelas formas lingüísticas que entram em sua composição (as palavras, as formas morfológicas ou sintáticas, os sons, as entoações), mas igualmente pelos elementos não verbais da situação. (...) Além do tema, ou, mais exatamente, no interior do tema, a enunciação é igualmente dotada de uma significação » (Bakhtin, 1986, p.128129)

Uma referência sempre presente no que tange às contribuições de Bakhtin é a distância que separa dialogismo e monologismo. Eis um dos momentos da reflexão de Bakhtin a propósito da perspectiva dialógica:

[Dostoievski sabia] captar o diálogo de sua época ou, mais exatamente, ouvir sua época no bojo de um grande diálogo, ali apreender não apenas as diversas vozes, mas, antes de tudo, apreender as relações dialógicas entre essas vozes, sua interação dialógica. Ele ouvia tanto as vozes instituídas, isto é, as principais idéias vigentes ... como as vozes ainda fracas, as idéias em desenvolvimento, e também as idéias secretas, percebidas apenas por ele, as idéias que apenas começavam a amadurecer, os embriões das futuras visões de mundo. (Bakhtin, 1970, p. 131-132).

Com efeito, a noção de dialogismo se constrói precisamente em oposição ao modo como o autor se refere à abordagem monológica, vista como « unificação de perspectivas », 
« estabilização de sentidos que se representam ». Tal concepção de monologismo se define pela existência de uma terceira pessoa, um eu monológico, que assumiria a tarefa de unificar a confrontação de autor e personagem. É precisamente esse « eu monológico » que inexiste na narrativa de Dostoievski, onde, nos termos de Bakhtin, os contrários coexistem numa lógica do sonho.

A ciência de tal visão polifônica das práticas linguageiras, que lidará com a palavra plena, com a pluralidade de vozes, de acentos, de muitos « outros », será não a lingüística, mas o que se designou «translingüística », território cuja exploração estará apoiada na noção de interação. Segundo Bakhtin, uma teoria da expressão comprometida com o modo pelo qual as práticas linguageiras produzem sentido não pode desconsiderar a realidade da interação verbal, lugar por excelência de determinação das condições de enunciação:

...a enunciação é o produto da interação de dois indivíduos socialmente organizados ... a palavra dirige-se a um interlocutor: ela é função da pessoa desse interlocutor: variará se se tratar de uma pessoa do mesmo grupo social ou não, se esta for, inferior ou superior na hierarquia social, ... (Bakhtin, 1986, p.112)

É exatamente o primado da interação verbal que vem colocar em cena o que denominei neste trabalho «circulação dos sentidos no espaço»: se se ratifica com Bakhtin uma «vocação social » da atividade mental do sujeito e da própria estrutura da enunciação, se se fala reiteradas vezes de um certo « fenômeno social da interação verbal », deve-se compreender que social, nesse contexto, remete ao encontro de várias individualidades. Em outras palavras, constata-se que social, em Bakhtin, muitas vezes coincide com interindividual ${ }^{9}$, razão pela qual considero ser esta uma versão fraca da mobilidade dos sentidos. Assim, se dizemos que o sentido circula nesta primeira acepção é porque é construído a várias vozes, num jogo que implica a co-presença de pelo menos dois interlocutores:

... toda palavra comporta duas faces. Ela é determinada tanto pelo fato de que procede de alguém, como pelo fato de que se dirige para alguém. Ela constitui justamente o produto da interação do locutor e do ouvinte (...) A palavra é uma espécie de ponte lançada entre mim e o outro. (Bakhtin, 1986, p.113)

\section{INSUFICIÊNCIAS DE UM ENFOQUE DA PRODUÇÃO DO SENTIDO NO ESPAÇO}

Se pensamos em uma outra forma de atualização da circulação do sentido, a saber, a circulação no tempo, é porque o primeiro modo apresentado - a circulação no espaço não parece ser suficiente para dar conta de tudo o que se encontra implicado com a produção do sentido. Por quê? Porque, se é verdade, segundo foi visto, que o sentido circula, ele

\footnotetext{
${ }^{9}$ Sobre a «coincidência» entre o interindividual e o social, veja-se a seguinte citação (grifos nossos): «Para que o objeto ... entre no horizonte social do grupo ..., é indispensável que ele esteja ligado às condições sócio-econômicas do referido grupo ... (...) é portanto indispensável que o objeto adquira uma significação interindividual ... Em outras palavras, não pode entrar no domínio da ideologia ... senão aquilo que adquiriu um valor social.» (Bakhtin, 1986, p. 45).
} 
ROCHA - O que queremos dizer...

circula ... de uma individualidade fechada para outra! Com efeito, penso que poderá ser produtiva uma abordagem capaz de superar um certo entendimento da circulação dos sentidos numa perspectiva ainda excessivamente presa às evidências do empírico, à individualização dos corpos, situação na qual o sentido seria o produto de uma « orquestração de vozes que apenas se somam", ou seja, situação na qual social equivaleria a interindividual; em poucas palavras, manifestação de uma certa concepção de sujeito ainda caudatária da ótica racional cartesiana: a presença do outro se reduz à entrada em cena de mais uma consciência (problema da ordem do meramente quantitativo), uma outra consciência tão plena e fechada quanto o seu mesmo; uma única lógica dá sustentação à inscrição desse outro, que não é senão o mesmo que se multipla infinitamente no espaço; um outro que vem apenas «clonar » o seu mesmo, reproduzindo uma suposta natureza humana já de longa data conhecida.

Prevalece, pois, o sujeito da razão nesse modo de produção de sentido que chamei de «circulação do sentido no espaço»: uma voz se revezando com outra(s), num jogo ininterrupto de alternâncias ao longo do qual ainda se mantém uma concepção fechada de sujeito, excessivamente individuada. Não é difícil perceber que, no contexto explicitado, o que se denomina social é apenas o encontro de duas individualidades.

Uma única citação acerca da problemática do dialogismo em Dostoievski deverá ser suficiente para sustentar o ponto de vista segundo o qual muitas das reflexões de Bakhtin parecem permanecer excessivamente presas às evidências de um sujeito individuado que não faz senão multiplicar-se ${ }^{10}$ :

O eu consciente, julgando o mundo enquanto seu objeto, não está só, mas se torna vários 'eu'. Dostoievski ultrapassa o solipsismo. (...). Em lugar das relações entre o 'eu' consciente e o mundo, ele coloca no centro de sua obra o problema das inter-relações entre esses diferentes 'eu' conscientes e críticos. (Bakhtin, 1970, p. 144)

Como será possível fazer circular o sentido que não seja de uma individualidade (fechada) para outra? Como superar o solipsismo que não seja fazendo dialogarem « diferentes 'eu' conscientes e críticos »?

\section{RESGATANDO A CIRCULAÇÃO NO TEMPO}

Aqui, pretendo já enfatizar a segunda perspectiva anunciada como norteadora deste trabalho, a saber, a circulação de sentidos no tempo, perspectiva que introduzo por intermédio de um duplo debate: o debate acerca das falácias de toda e qualquer idéia de ordenação / hierarquização entre um significado fixo ao qual viria se acrescentar um sentido (acessório) mutante; o debate acerca da impossibilidade de circunscrição dos sentidos nos limites do sujeito da razão.

\footnotetext{
${ }^{10} \mathrm{O}$ que não significa que, em outros momentos de sua obra, Bakhtin não entreveja outra forma de pensar o sujeito, como parece ser o caso do tratamento dispensado pelo autor à noção de superdestinatário (Bakhtin, 1992, p. 356), ou ainda à noção de pluriacentuação, que retomo em 6.1.
} 


\title{
6.1 O dicionarizado e o não reiterável
}

Para além das noções de tema e significação, que obviamente são relevantes no debate acerca da circulação de sentido, considero que a reflexão de Authier-Revuz (2004) sobre a afinidade existente na obra bakhtiniana entre o plano dialógico e a constituição do sentido represente uma contribuição da maior importância para o atual debate. Evocando a idéia de pluriacentuação, a autora coloca em cena a inadequação de um enfoque que se assente na mera polarização entre sentido denotativo e sentido(s) derivado(s). Assim, AuthierRevuz lembra que a pluriacentuação não pode ser vista como mero detalhe conotativo que se superporia a um núcleo de sentido comum de um enunciado, devendo, antes, ser apreendida como a atualização de acentos contraditórios que habitam o interior de cada palavra, o que coloca em jogo o entrecruzamento de discursos como lugar onde se faz o sentido.

O significado não pode, portanto, ser um primeiro, algo ao qual viria se somar um depois, um sentido:

\begin{abstract}
« Não há um 'sentido em si'. O sentido só existe para outro sentido ... Por isso não pode haver um sentido primeiro ou último, pois o sentido se situa sempre entre os sentidos, elo na cadeia do sentido que é a única suscetível, em seu todo, de ser uma realidade. » (Bakhtin, 1992, p. 386).
\end{abstract}

Se não é lícito descrever o processo em termos de um antes (fixo) e um depois (variável), como preceder então? Uma resposta sintética descreveria o processo remetendo a um congelamento - sempre provisório - de traços que se dicionarizam em função de práticas linguageiras tidas como majoritárias, o plano do instituído, que nada tem de natural e que podemos desconstruir em seus dispositivos de reprodução; tais planos congelados encontrariam seus pontos de desestabilização para que novas linhas de fuga ${ }^{11}$ possam se produzir.

A vantagem de tal perspectiva que recusa a mera superposição de camadas (das mais antigas e sedimentadas às mais recentes e inconsistentes) é a seguinte: postular um momento primeiro de estabilidade ao qual se somaria um outro de maior fluidez implicaria assumir uma perspectiva representacional da linguagem em seu sentido forte, ou seja, implicaria a existência de um mundo previamente instaurado, de significações estabilizadas, que daria apoio à representação (dimensão ontológica do conceito); o conhecimento seria algo de objetivo, pois corresponderia em todos os pontos, e de forma absolutamente adequada, ao mundo (dimensão epistemológica do conceito) ${ }^{12}$.

Rejeitando as consequiências de tal concepção para o presente debate acerca da circulação de sentido, parece-me preferível aceitar um entendimento de representação como tão-somente um dos momentos necessários a que virtualidades ganhem corpo em

${ }^{11}$ Segundo Deleuze e Guattari, a noção de linhas de fuga refere-se a vetores de desterritorialização, isto é, à possibilidade de se superar a clausura das formas instituídas do pensamento estruturalista binarizado e hierarquizante (humano-animal, masculino-feminino, etc.).

${ }^{12}$ Em sustentação à perspectiva representacional (em seu sentido forte), que atribuiria um lugar de precedência às formas delimitadas, às significações estabilizadas, assitimos à identificação entre sentido e verdade (como em Aristóteles). 
ROCHA - O que queremos dizer...

decorrência da experiência, ou seja, acatar a atividade de representação como não constitutiva de nossa relação com o real. Nessa versão fraca da noção de representação, a representação se dará, sim, mas como uma estabilização provisória de uma conduta ou solução cognitiva, sempre aberta a problematizações posteriores.

Assim, o significado, enquanto estabilização momentânea, corte em um fluxo, reenviaria ao trabalho incessante de atualização de novas significações - estando aqui o acento no concreto, na enunciação irrepetível. Posição, aliás, que também diz algo acerca do que seja conhecer o mundo: conhecer o mundo é muito mais do que representá-lo; é problematizá-lo, é conceder prioridade ao concreto, ao presente imediato, é dar lugar à produção de territórios experienciais e emergentes das interações e acoplamentos (Kastrup, 1999, p.128).

Falaríamos, pois, de sentido em relação de complementaridade / alteridade a significado, ou a significação, como querem alguns autores, como algo da ordem dos encontros que se atualizam entre o estabilizável e o em movimento; o retrato e o filme; o dicionário e a intensidade de um mundo de interações, a vida mesma em sua potência expressiva; identidade e alteridade; ou, ainda, identidade e processos múltiplos de identificação.

\subsection{Para além do sujeito da razão: sentido, multiplicidade de forças e devir}

Argumentou-se no item anterior que a circulação dos sentidos tem tudo a ver com um distanciamento em relação ao controle exercido pelas formas da representação, uma fuga à formação de hábitos cristalizados. Circulação de sentidos como operação de dupla captura: sujeito e mundo não são essências apriorísticas; antes, produzem-se em formas sempre provisórias e em correspondência. A esse respeito, encontramos nas reflexões de Nietzsche elementos que contribuem fortemente para reafirmar esse mesmo ponto de vista.

De que modo Nietzsche poderá ajudar a pensar tal ciranda entre formas estabilizadas (significado) e movimento (sentido)? Em outras palavras, de que modo se daria a produção de um plano de estabilidades, de significados reiteráveis, que permanecem sempre os mesmos, em alternância (num continuum) com um outro plano de sentidos que deslizam, que nunca permanecem e que se definem apenas momentaneamente em função da situação de enunciação em que ocorrem ${ }^{13}$ ?

Na crítica empreendida por Nietzsche, é um novo modo de apreender a relação homem - mundo que possibilitará superar o modelo do sujeito da razão. Com efeito, o que marca a busca humana por conhecimento é a impossibilidade do conhecimento verdadeiro, própria de um mundo marcado pelo devir. É essa impossibilidade que leva à criação da rede de fixações e sentidos, essa rede de ficções chamada lógica, forma de escravidão voluntária do homem. O universo conceitual que o homem construiu, sustentado pela ordem lógica

${ }^{13}$ Esclareço, seguindo a advertência feita por Possenti (2002, p. 234), que, se falamos de alternância entre um pólo de formas estabilizadas e um pólo em movimento que sempre estará na dependência de uma dada situação de enunciação, isto não significa que o referido movimento seja sempre produtor de formas « novas e irrepetíveis ». 
do discurso, resulta não de uma constatação, de uma « verdade », mas de uma necessidade (necessidade que, segundo Nietzsche, é um sintoma do homem gregário, do homem fraco).

Nietzsche (2004, p.195-196; 1987a) explora a relação entre linguagem e gregariedade, linguagem e comunicação: como o animal mais ameaçado, mais frágil, o homem encontrou no agrupamento sua possibilidade de sobrevivência. Para tal, precisou de um sistema de signos que permitisse a comunicação e o acordo. Assim, o mundo da identidade e da verdade teria surgido quando um determinado sistema metafórico teve de ser imposto a todos. Logo, para Nietzsche (1987a), é a existência social do homem que exige a linguagem fundada na identidade. A vida gregária necessita do acordo entre os homens (Mose, 2005, p.75), o que se obtém por intermédio dos conceitos, que não são senão metáforas mortas: a identidade é a sustentação desse acordo, e a verdade é mera obediência a uma dada convenção.

Para haver comunicação, é preciso que as pessoas tenham uma experimentação comum das coisas. Tal experimentação corresponde à vida em rebanho, corresponde à eliminação da diferença: é preciso usar as mesmas palavras para a mesma espécie de vivências interiores; nesse sentido, a grande função da gregariedade é impedir a proliferação de interpretações e valores.

A consciência (aparelho internalizado de signos) em Nietzsche (1987a) deriva da linguagem, ambas sendo o resultado de uma necessidade humana de comunicação e acordo. Segundo o autor, o que a consciência (que não tem nada de individual) faz é reduzir o pensamento a palavras, para garantir a sobrevivência. Cria, pois, um modo de pensamento que é apenas a esquematização da linguagem e, por extensão, produz a idéia de $e u$ :

A razão é a órbita capaz de fazer o pensamento girar em torno da mesma idéia: a identidade, a
causalidade, a não-contradição do ser. É a linguagem quem « advoga » a favor do erro metafísico
do ser ... (...) Utilizar a linguagem metafísica, a razão, é projetar a identidade - «eu substância»-
para todas as coisas: o mundo se torna um mundo de entidades observáveis, de «coisas». (Mose,
2005, p.142-143)

Para Nietzsche, é a crença no sujeito (o sujeito da razão) que permite a substancialização da realidade: a compreensão de algo como irredutível, de algo idêntico a si, somente é possível porque acreditamos encontrar em nós mesmos o exemplo dessa identidade.

Vê-se, assim, que a crença no sujeito (em Nietzsche, também chamado « eu », « alma », « espírito », « vontade », « consciência ») pressupõe basicamente as noções de interioridade, unidade e princípio. Quanto à consciência (segunda camada de sentido como sustentação da subjetividade moderna), trata-se de algo como uma ponte entre a interioridade e a exterioridade, traduzindo as forças da vida (inconscientes) para o mundo dos códigos, da linguagem.

Segundo Mose (2005), em dois pólos da história do conhecimento, a saber, a racionalidade socrático-platônica e o cristianismo, de um lado, e a modernidade, de outro, encontramos, respectivamente, a idéia de ser como duração e verdade, e a idéia de sujeito, como representação da autonomia da razão. «É da idéia de ser que nasce a identidade, a unidade, a verdade, a causa, que, na modernidade, vão ser atribuídos ao sujeito de conhecimentos.» (Mose, 2005, p.184). 
ROCHA - O que queremos dizer...

Que alternativa é oferecida por Nietzsche a tal condição?

$\mathrm{Se}$, nos moldes cartesianos, o pensamento é fruto de uma causa (o « eu », o agente que pensa), para Nietzsche (2004, p. 46), o pensamento não resulta de um ponto, de uma intenção, de um eu, mas de uma guerra de fluxos: por trás de todo pensamento existem paixões que se chocam e que o eu busca aplacar. Logo, o pensamento é uma ficção: ele não é uma « realidade », nem o sujeito é uma substancialidade. «Pensar é uma simplificação da pluralidade instintiva.» (Mose, 2005, p.182).

O pensamento, enquanto atividade interpretativa própria da vida, vai muito além da mencionada necessidade de comunicação. E Nietzsche (1987b) acredita na possibilidade de a linguagem contemplar a singularidade, a força, a potência. Em outras palavras, acredita numa linguagem afirmativa, que atraia a pluralidade. Como?

«A metáfora é uma positividade da linguagem, na medida em que manifesta, mesmo através de transposições, a multiplicidade estética que é a vida» (Mose, 2005, p.190). O problema não é, pois, a natureza metafórica da linguagem, mas a decisão a partir da qual a metáfora é afirmada como verdade, isto é, quando se torna conceito como necessidade da gregariedade: na formação do conceito, o que ocorre é a própria negação da capacidade metafórica da linguagem.

Uma alternativa possível seria apreender o signo como jogo de forças, e não como verdade. O signo apenas configura, apenas esquematiza algo; sua função não é revelar. Logo, «como um contorno vazio exposto ao jogo de forças da vida, o que o signo traduz é o resultado provisório de uma luta» (Mose, 2005, p.86). Tal entendimento do signo é compatível com o modo como Nietzsche entende a origem da linguagem, a qual teria nascido da música como manifestação de uma melodia primordial, de uma melodia dos afetos. Tal música, impossível de ser simbolizada, não possui forma: é o dionisíaco ${ }^{14}$. No referido contexto, a produção de formas estabilizadas, que apenas provisoriamente interromperiam a música dionisíaca, correponderia ao momento da representação formal e luminosa da transposição apolínea.

Ambas as positividades (linguagem como música e como metáfora) foram negadas pela cultura socrática. Como metáfora (transposição) e música (intensidades), a linguagem estaria situada no plano dos sentidos que circulam, dos encontros entre os corpos, e não no plano das representações ${ }^{15}$. Por extensão, as metáforas congeladas, responsáveis pelos conceitos que se dão por eternos e que implicam o afastamento dos corpos, remeteriam ao plano do significado. Aqui percebe-se que o plano dos significados dicionarizados apresenta-se como decorrente de um exercício de poder que se cristaliza como forma-verdade.

\section{7. À GUISA DE CONCLUSÃO: O DESAFIO DE UMA NOVA CONCEPÇÃO DE SUBJETIVIDADE}

Neste artigo, centramo-nos no debate segundo o qual o abandono do paradigma que defende a estabilidade dos sentidos não se dá de forma linear. Pelo contrário, vimos que uma

\footnotetext{
${ }^{14}$ De tal música originária derivaria a música propriamente dita (esta foi quem guardou maior proximidade com a música dionisíaca), a poesia lírica e épica, a linguagem prosaica e a científica.

${ }^{15}$ Pelo fato de a linguagem não mais estar submetida à lógica do plano da representação, falo agora de versão forte da mobilidade dos sentidos.
} 
primeira resposta aos que preconizam uma maior estabilidade dos sentidos - posição que ilustramos recorrendo à Análise do Conteúdo, abordagem em estreita afinidade com o behaviorismo americano da primeira metade do século XX - configura o que denominamos «circulação dos sentidos no espaço». Tal modo de atualização da mobilidade dos sentidos pode ser considerado como uma versão fraca da mobilidade, uma vez que nele permanecemos prisioneiros de uma certa concepção de sujeito em harmonia com a visão cartesiana de um sujeito da razão.

Acreditamos que a proposta de AD desenvolvida a partir de Pêcheux tenha obtido êxito na superação de uma leitura « ingênua » ou « naturalizada » das práticas linguageiras, garantindo-lhes a necessária opacidade no tratamento dos fenômenos relativos à produção de sentidos, tendo em vista principalmente as alianças que pôde estabelecer com o marxismo e a psicanálise. Com efeito, a entrada em cena de noções como as de ideologia e inconsciente em articulação com o lingüístico marcam um significativo avanço nas possibilidades de leitura de um texto. Contudo, ainda mantém a possibilidade de reatualização das abstrações totalizantes, de um princípio racional transcendente disciplinador do real. Os fragmentos a seguir são ilustrativos do modo como as noções de ideologia e inconsciente podem se constituir em vetores de aprisionamento no interior de uma mesma lógica de sujeito da razão, tendo em vista o que poderíamos denominar «as armadilhas da representação»:

\begin{abstract}
«A noção de ideologia não nos permite compreender essa função literalmente produtiva da subjetividade. A ideologia permanece na esfera da representação, quando a produção essencial do CMI [capitalismo mundial integrado] não é apenas a da representação, mas a de uma modelização que diz respeito aos comportamentos, à sensibilidade, à percepção, à memória, às relações sociais, às relações sexuais, aos fantasmas imaginários, etc. ». (Guattari \& Rolnik, 1986, p.28)

«... grande parte das conceptualizações do inconsciente - sejam elas originárias de desdobramentos ou diversificações dentro do campo psicanalítico ou simplesmente de diferentes óticas de leitura da obra de Freud - nascem e crescem à sombra da tradição teórica aberta por Platão, geralmente designada por filosofia da representação.» (Naffah Neto, 1991, p.15)
\end{abstract}

Se digo que a perspectiva discursiva desenvolvida a partir de Pêcheux garantiu um terreno propício a um certo enfoque da mobilidade dos sentidos em sua versão fraca, isto não significa, a meu ver, que estejamos num campo incompatível com o que foi denominado «versão forte». Pelo contrário, creio ser possível percorrer outros caminhos que permitam destronar a referida centralidade da noção de representação, repensando-se o perfil de formulações como as que caracterizam os planos do ideológico e do inconsciente ${ }^{16}$. Os fragmentos que transcrevo a seguir parecem indicar pistas seguras para o mencionado trabalho de reformulação do conceito de ideologia:

«Ao invés de ideologia, prefiro falar sempre em subjetivação, em produção de subjetividade. (...) ... não mais consideramos a produção de subjetividade como sendo apenas um caso de superestrutura, ... [mas] como sendo a matéria-prima da evolução das forças produtivas ... » (Guattari \& Rolnik, 1986, p.25-26)

${ }^{16}$ A reformulação das noções de ideologia e inconsciente a que ora me refiro ultrapassa em muito os limites do presente artigo, razão pela qual o que se segue deve ser compreendido como pistas cuja produtividade poderá ser investigada em trabalhos futuros. 
ROCHA - O que queremos dizer...

Quanto à noção de inconsciente, retomo mais uma vez aqui a reflexão de Naffah Neto (1991) que, após se referir a um inconsciente apresentado como prisioneiro do « domínio da consciência, das suas representações, dos seus códigos morais » (Naffah Neto, 1991, p. 34), defende uma outra concepção largamente inspirada em Nietzsche:

\begin{abstract}
« Há um outro inconsciente ... que designa antes aquelas dimensões do sentir que resistem aos processos de representação, que não cabem nos códigos, que permanecem marginais a eles. Esse inconsciente não designa nada de oculto (...) Ele designa um universo indizível, marginal à consciência e com o qual é preciso entrar em ressonância. Invisível e indizível, porque é fluxo, devir, sem forma ou representação definida, campo de forças móveis e vibráteis. » (Naffah Neto, 1991, p. 34)
\end{abstract}

Fechando a presente discussão, quero aqui apenas indicar pistas para uma certa forma de pensar a questão da circulação dos sentidos que ganha um perfil singular a partir das reflexões de Guattari. Com efeito, a contribuição de maior relevância do autor reside precisamente em nos fornecer elementos que favorecerão ultrapassar os limites de uma abordagem que privilegie o sujeito da razão, indo além do plano das formas espacializadas. Cito Guattari:

O sujeito, segundo toda uma tradição da filosofia e das ciências humanas, é algo que encontramos como um 'être-là', algo do domínio de uma suposta natureza humana. Proponho, ao contrário, a idéia de uma subjetividade de natureza industrial, maquínica, ou seja, essencialmente fabricada, modelada, recebida, consumida . (Guattari, 1992, p.25)

Falar de circulação de sentidos não pode, pois, coincidir com uma perspectiva que se restrinja à mera passagem de um sujeito pleno a outro, num « revezamento de sucessivos sujeitos-ilhas » tão ao gosto da lição de Descartes. O perigo em tais casos consiste em se permanecer numa concepção essencializada, individualizada, substancializada, de sujeito.

Como ultrapassar tal limitação? Incluindo problemáticas sociais, econômicas, políticas, tecnológicas e estéticas para um alargamento da noção de subjetividade - dirá Guattari. E mais: assumindo plenamente a natureza coletiva dessa subjetividade, o que se traduz na adoção do conceito de agenciamentos coletivos de enunciação ${ }^{17}$ :

Ao invés de sujeito, de sujeito de enunciação ou das instâncias psíquicas de Freud, prefiro falar em agenciamento coletivo de enunciação. $\mathrm{O}$ agenciamento coletivo não corresponde nem a uma entidade individuada, nem a uma entidade social predeterminada. (Guattari \& Rolnik, 1986, p. 30-31)

Repensar a noção de sujeito e, por extensão, redefinir as condições nas quais se dá a circulação de sentidos significa acima de tudo desconstruir um sujeito visto como essência última da individualização, como elemento unificador de estados de consciência ${ }^{18}$; significa ainda desfazer todo um modo de pensar nossa relação com a linguagem, que vem se alimentando de uma ótica binária, a exemplo de oposições como sujeito $\mathrm{X}$ objeto,

${ }^{17}$ A respeito da noção de agenciamentos coletivos de enunciação, ver Rocha, 2004.

${ }^{18}$ Conforme foi exposto no item 2 deste trabalho, podemos constatar, já em Pêcheux, os estreitos laços que unem o debate acerca de uma certa concepção de sujeito e de sentido. 
consciência X mundo, corpo X alma, individual X social; significa, portanto, desnaturalizar tais polarizações, investigando-se as condições de existência de diferentes formas-sujeito constituídas historicamente.

Entendo como bastante produtivo o ponto de vista defendido por Guattari. Produtivo e, por isso mesmo, promissor, no que diz respeito aos estudos voltados para uma perspectiva discursiva. Eis a razão pela qual este trabalho se conclui por uma espécie de convite a que se percorra o caminho indicado pelo autor para abordar esse funcionamento polifônico da subjetividade no que tange à produção do sentido.

\section{REFERÊNCIAS BIBLIOGRÁFICAS}

AUTHIER-REVUZ, J. (2004). Entre a transparência e a opacidade: um estudo enunciativo do sentido. Porto Alegre: EDIPUCRS. 257 p.

BAKHTIN, M. (1970). La poétique de Dostoievski. Paris: Seuil. 349 p. (1986). Marxismo e Filosofia da linguagem. São Paulo: Hucitec. 196 p. (1992). Estética da criação verbal. São Paulo: Martins Fontes. 421 p.

BLOOMFIELD, L. (1970). Le langage. Paris: Payot. 524 p.

BOUTET, J. (1994). Construire le sens. Berna, Berlim, Frankfurt: Peter Lang. 236 p.

BRAIT, B. (2001). O discurso sob o olhar de Bakhtin. In: GREGOLIN, M. do R.; BARONAS, R. (Orgs.) Análise do discurso: as materialidades do sentido. São Carlos, SP: Claraluz. 230 p.

GREGOLIN, M. do R. (2001). Sentido, sujeito e memória: com o que sonha nossa vã autoria?. In: GREGOLIN, M. do R.; BARONAS, R. (Orgs.) Análise do discurso: as materialidades do sentido. São Carlos, SP: Claraluz. 230 p.

GUATTARI, F. (1992). Caosmose: um novo paradigma estético. Rio de Janeiro: Ed.34. 203p.

GUATTARI, F. \& ROLNIK, S. (1986). Micropolítica: cartografias do desejo. Petrópolis: Vozes. 327p.

KASTRUP, V. (1999). A invenção de si e do mundo. Campinas, SP: Papirus. 216 p.

MOSE, V. (2005). Nietzsche e a grande política da linguagem. Rio de Janeiro: Civilização Brasileira. 237 p.

NAFFAH NETO, A. (1991). O inconsciente como potência subversiva. São Paulo : Escuta. 72 p.

NIETZSCHE, F. (1987a). Sobre verdade e mentira no sentido extra-moral. In: Obras incompletas / Friedrich Nietzsche. 4a. ed. São Paulo: Nova Cultural, p.29-38. (Os pensadores).

. (1987b). O nascimento da tragédia no espírito da música. In: Obras incompletas / Friedrich Nietzsche. 4a. ed. São Paulo: Nova Cultural, p. 5-28. (Os pensadores).

(2004). Para além do bem e do mal - prelúdio a uma filosofia do futuro. São Paulo: Martin Claret. $228 \mathrm{p}$.

ORLANDI, E. (2002). Língua e conhecimento lingüístico - para uma história das idéias no Brasil. São Paulo: Cortez. 320 p.

PÊCHEUX, M. (1988). Semântica e discurso: uma crítica à afirmação do óbvio. Campinas: Ed. da UNICAMP. $317 \mathrm{p}$. 
ROCHA - O que queremos dizer...

PEYTARD, J.; MOIRAND, S. (1992). Discours et enseignement du français - les lieux d'une rencontre. Paris: Hachette. 223 p.

POSSENTI, S. (2001). Ainda sobre a noção de efeito de sentido. In: GREGOLIN, M. do R.; BARONAS, R. (Orgs.) Análise do discurso: as materialidades do sentido. São Carlos, SP: Claraluz. 230 p. . (2002). Os limites do discurso. Curitiba: Criar. 260 p.

ROCHA, D. (2004). Agenciamentos coletivos de enunciação e discursos midiáticos. Semiosfera, 8, ano 5, Rev. de Pós-graduação Eco-UFRJ. Disponível em : www.eco.ufrj.br/semiosfera. Acesso em: 18 julho 2005.

ROCHA, D.; DEUSDARÁ, B. (2006). Análise de Conteúdo e Análise do Discurso: o lingüístico e seu entorno. D.E.L.T.A., São Paulo, v. 22, p. 29-52. 